\title{
Topical dorzolamide for macular edema in the early phase after vitrectomy and epiretinal membrane removal
}

This article was published in the following Dove Press journal:

Clinical Ophthalmology

18 April 2013

Number of times this article has been viewed

\section{Takahiro Suzuki \\ Kenji Hayakawa \\ Yoshihiro Nakagawa \\ Hiromi Onouchi \\ Masafumi Ogata \\ Kenji Kawai}

Department of Ophthalmology, Tokai University School of Medicine, Isehara, Japan
Correspondence: Takahiro Suzuki Department of Ophthalmology, Tokai University School of Medicine, 143 Shimokasuya, Isehara, Kanagawa 259-I I 43, Japan

Tel $+8 \mid 46393$ II 2 I

Fax +8I 463919328

Email youta@is.icc.u-tokai.ac.jp
Background: The purpose of this study was to evaluate prospectively the efficacy of a topical carbonic anhydrase inhibitor in macular edema after vitrectomy.

Methods: Forty patients were included, all of whom had undergone vitrectomy combined with phacoemulsification and intraocular lens implantation for epiretinal membrane. Twenty eyes from 40 patients received topical $2 \%$ dorzolamide three times a day. The patients were followed up for at least 3 months. In this study, we evaluated the effect of dorzolamide on visual acuity, intraocular pressure, central macular thickness, and aqueous flare.

Results: Mean logarithm of the minimum angle of resolution (logMAR) best-corrected visual acuity preoperatively and 2 weeks, 1 month, and 3 months after surgery was $0.48 \pm 0.23,0.60 \pm 0.16$, $0.40 \pm 0.29$, and $0.24 \pm 0.32$, respectively, in the treatment group, and $0.40 \pm 0.09,0.44 \pm 0.12$, $0.32 \pm 0.10$, and $0.16 \pm 0.09$, respectively, in the control group. No statistically significant difference was observed between the two groups. Mean central macular thickness preoperatively and at 2 weeks and 3 months after surgery was $572.6,427.2$, and $333.4 \mu \mathrm{m}$, respectively, in the treatment group, and 571.4, 485.2, and $388.4 \mu \mathrm{m}$, respectively, in the control group. Mean aqueous flare preoperatively, and 1 month and 3 months after surgery was 8.6, 34.2, and 23.5 photon counts per millisecond (pc/ms), respectively, in the treatment group, and 9.7, 24.7, and $23.4 \mathrm{pc} / \mathrm{ms}$, respectively, in the control group. No statistically significant differences were observed between data from the two groups. However, statistically significant $(P<0.05)$ differences in mean central macular thickness at 1 month and mean aqueous flare at 2 weeks after surgery were found between the treatment group ( $358.8 \mu \mathrm{m}, 36.8 \mathrm{pc} / \mathrm{ms})$ and the control group $(467.8 \mu \mathrm{m}, 64.0 \mathrm{pc} / \mathrm{ms})$. Differences in mean intraocular pressure preoperatively and at 2 weeks, 1 month, and 3 months after surgery were not statistically significant between the two groups. Intraocular pressure never exceeded $21 \mathrm{mmHg}$.

Conclusion: Topical dorzolamide significantly reduced mean central macular thickness at 1 month and mean aqueous flare at 2 weeks after surgery for epiretinal membrane compared with controls. Although further investigation of more cases and longer follow-up are needed, this study suggests that topical dorzolamide can be efficacious in reducing macular edema in the early phase after vitrectomy via its anti-inflammatory effect.

Keywords: macular edema, dorzolamide, epiretinal membrane, vitrectomy, anti-inflammatory

\section{Introduction}

Dorzolamide is a topical carbonic anhydrase inhibitor and is used widely in the treatment of glaucoma. Macular edema results from breakdown of the blood-retinal barrier, vitreous traction, and damage to the retinal pigment epithelial cells, leading to accumulation of intracellular and extracellular fluid. ${ }^{1-7}$ Macular edema occurs in a variety of pathologic conditions, including diabetic retinopathy, central and branch retinal vein occlusions, uveitis, retinitis pigmentosa, epiretinal membrane, and other 
nutritional and metabolic diseases, as well as after surgery. Recently, clinical interest has focused on retinal disorders as an indication for this drug. Since the first report by Cox in $1988,{ }^{8}$ several authors have described a positive effect of acetazolamide on the resolution of macular edema from various etiologies, including uveitis and postoperative inflammation after cataract extraction, ${ }^{9}$ retinitis pigmentosa, ${ }^{10}$ and serpiginous choroiditis, ${ }^{11}$ and in conjunction with epiretinal membrane. ${ }^{12}$ Findings on optical coherence tomography and improvement in visual acuity have demonstrated that dorzolamide has a curative effect on the macular cystic cavities found in congenital X-linked retinoschisis, ${ }^{13}$ choroideremia, ${ }^{14}$ and retinitis pigmentosa. ${ }^{15}$ The pathogenesis of macular edema often involves a multifactorial background. We have reported that dorzolamide had an anti-inflammatory effect in a comparative study of eye drops in the treatment of glaucoma. ${ }^{16}$ In that research, we studied the efficacy of dorzolamide in the treatment of macular edema and inflammation, based on our experience of administration of dorzolamide eye drops to treat ocular hypertension after vitreous surgery. To study the efficacy of a drug for macular edema, an ideal subject should have macular edema that results from a single cause, and the cause should be removed. In this study, we chose patients who underwent vitrectomy and removal of epiretinal membrane. The purpose of this study was to determine the efficacy and safety of topical dorzolamide for treating macular edema.

\section{Materials and methods}

Forty patients with macular edema following removal of epiretinal membrane and who fulfilled the criteria for this study were enrolled. Any patients with pre-existing ocular disease (glaucoma, high myopia, chronic inflammatory, or neoplastic disorders), a systemic disorder (eg, diabetes or uncontrolled hypertension), or a known life-threatening disease were excluded prior to enrolment. The study was approved by the institutional review board at our institution. Patients were informed of the purpose of our study and provided their signed consent to participate. This study prospectively evaluated the primary outcomes of visual acuity, intraocular pressure, central macular thickness, and aqueous flare. The surgical technique used was 23-gauge pars plana vitrectomy. All patients underwent phacoemulsification and polyacrylic intraocular lens implantation (AN6K, Kowa, Tokyo, Japan). A vitrectomy was done with prior application of triamcinolone acetonide (Kenacort-A ${ }^{\circledR}$, Bristol Pharmaceuticals, Tokyo, Japan). In all eyes, the posterior hyaloid membrane was separated from the retinal surface with suction from the vitreous cutter. In the present study, the epiretinal membrane was removed using microforceps intraoperatively, but intentional removal of the internal limiting membrane was not performed in all cases. However, we could not exclude accidental removal of the internal limiting membrane during surgery. Postoperative treatment consisted of levofloxacin $0.5 \%$, dexamethasone $0.02 \%$, and diclofenac $0.1 \%$ eye drops applied topically three times daily for 1 month and oral cefcapene pivoxil hydrochloride $75 \mathrm{mg}$ or $100 \mathrm{mg}$ three times daily for 5 days, in all cases, in both groups. Twenty patients were randomly assigned in a prospective manner to receive dorzolamide three times a day. To evaluate the effects of treatment, all patients underwent a detailed ophthalmic examination, including slit-lamp biomicroscopy, optical coherence tomography, and a laser flare cell meter test (FC-2000, Kowa). Foveal configuration and retinal thickness were determined by optical coherence tomography, and retinal thickness was defined as the distance between the vitreoretinal interface and the retinal pigment epithelium in the center of the fovea. Aqueous flare was evaluated using a slit-lamp as well as a laser flare cell photometer, as described in detail in previous studies. ${ }^{17,18}$ Calibration was performed each day according to the manufacturer's instructions, to ensure accurate measurements. Measurements were taken in a standardized fashion by the same experienced technician who was blinded as to the medical condition of the patients. From each eye, three individual measurements were averaged, and measurements contaminated by artifacts were discarded. Flare reading was expressed as photon counts per millisecond (pc/ms). Best-corrected visual acuity was examined using the decimal visual acuity system in 40 eyes, which was converted to the logarithm of the minimum angle of resolution ( $\log M A R)$ scale. Goldmann tonometry was used to determine intraocular pressure. Safety was evaluated by determining the incidence of treatment-related complications and adverse reactions for both the treatment and control groups. The differences between the treatment group and the control group were assessed for statistical significance using the Student's $t$-test when appropriate. A level of $P<0.05$ was accepted as being statistically significant.

\section{Results}

Mean $\log$ MAR best corrected visual acuity preoperatively, and at 2 weeks, 1 month, and 3 months after surgery was $0.48 \pm 0.23,0.60 \pm 0.16,0.40 \pm 0.29$, and $0.24 \pm 0.32$, respectively, in the treatment group, and $0.40 \pm 0.09,0.44 \pm 0.12$, $0.32 \pm 0.10$, and $0.16 \pm 0.09$, respectively, in the control group. No statistically significant difference between the two groups was observed (Figure 1). The difference in mean 
intraocular pressure preoperatively, and at 2 weeks, 1 month, and 3 months after surgery between the treatment group and the control group was not statistically significant. Intraocular pressure never exceeded $21 \mathrm{mmHg}$ (Figure 2). Mean central macular thickness preoperatively and at 2 weeks, and 3 months after surgery was $572.6,427.2$, and $333.4 \mu \mathrm{m}$, respectively, in the treatment group, and 571.4, 485.2, and $388.4 \mu \mathrm{m}$, respectively, in the control group. No statistically significant difference between the two groups was observed, except that the difference in mean central macular thickness at 1 month after surgery was statistically significant $(P<0.05$, see Figures 3 and 4$)$ between the treatment group $(358.8 \mu \mathrm{m})$ and the control group $(467.8 \mu \mathrm{m})$.

Mean aqueous flare preoperatively and at 1 month, and 3 months after surgery was $8.6,34.2$, and $23.5 \mathrm{pc} / \mathrm{ms}$, respectively, in the treatment group, and 9.7, 24.7, and $23.4 \mathrm{pc} / \mathrm{ms}$, respectively, in the control group. No statistically significant difference was observed between the two groups, but the difference in mean aqueous flare at 2 weeks after surgery was statistically significant $(P<0.05)$ between the treatment group $(36.8 \mathrm{pc} / \mathrm{ms})$ and the control group $(64.0 \mathrm{pc} / \mathrm{ms}$, see Figure 5). Patients were monitored for any possible adverse effects that could be attributed to the drugs throughout the study. No significant systemic or ocular complications or adverse events occurred during the study.

\section{Discussion}

Epiretinal membrane traction is believed to stimulate inflammation, exudates, and a leukocyte response in the macula, leading to macular edema. The efficacy of anti-inflammatory agents, including triamcinolone acetonide and topical nonsteroidal anti-inflammatories, has been demonstrated

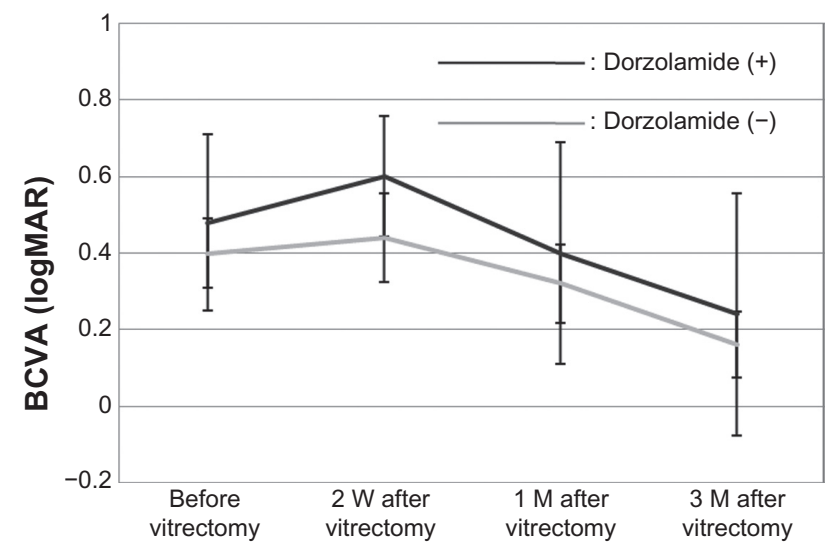

Figure I The mean logMAR best-corrected visual acuity preoperatively and at 2 weeks $(W)$, and I and 3 months $(M)$ after surgery was not significantly different between the treatment and control groups.

Abbreviations: BCVA, best corrected visual acuity; logMAR, logarithm of the minimum angle of resolution.

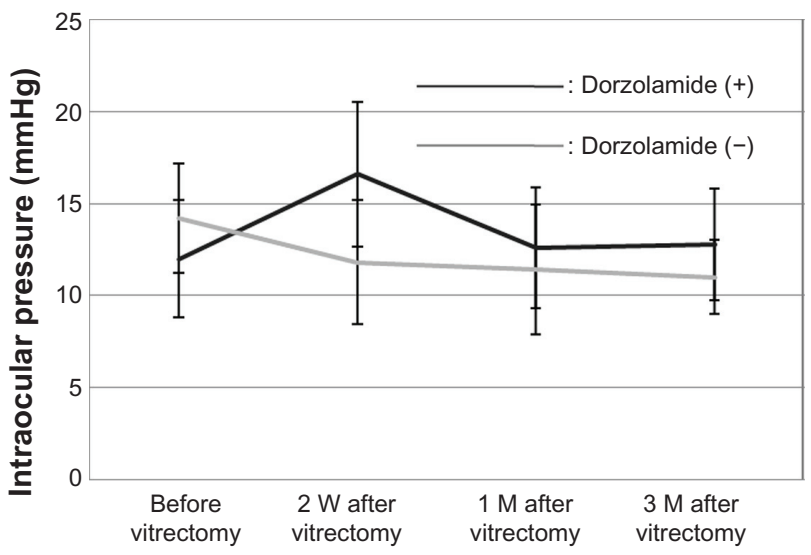

Figure 2 The mean intraocular pressure preoperatively and at 2 weeks $(\mathrm{W})$, and I and 3 months $(M)$ after surgery was not significantly different between the treatment and control groups, and intraocular pressure never exceeded $21 \mathrm{mmHg}$.

in several studies, both for the prevention and treatment of inflammatory macular edema. ${ }^{19}$ We have previously reported that dorzolamide suppresses production of the proinflammatory cytokine, interleukin-6, which is a major participant in the inflammatory process. ${ }^{16}$ It has been reported that in patients with rheumatoid arthritis already on $25 \mathrm{mg} /$
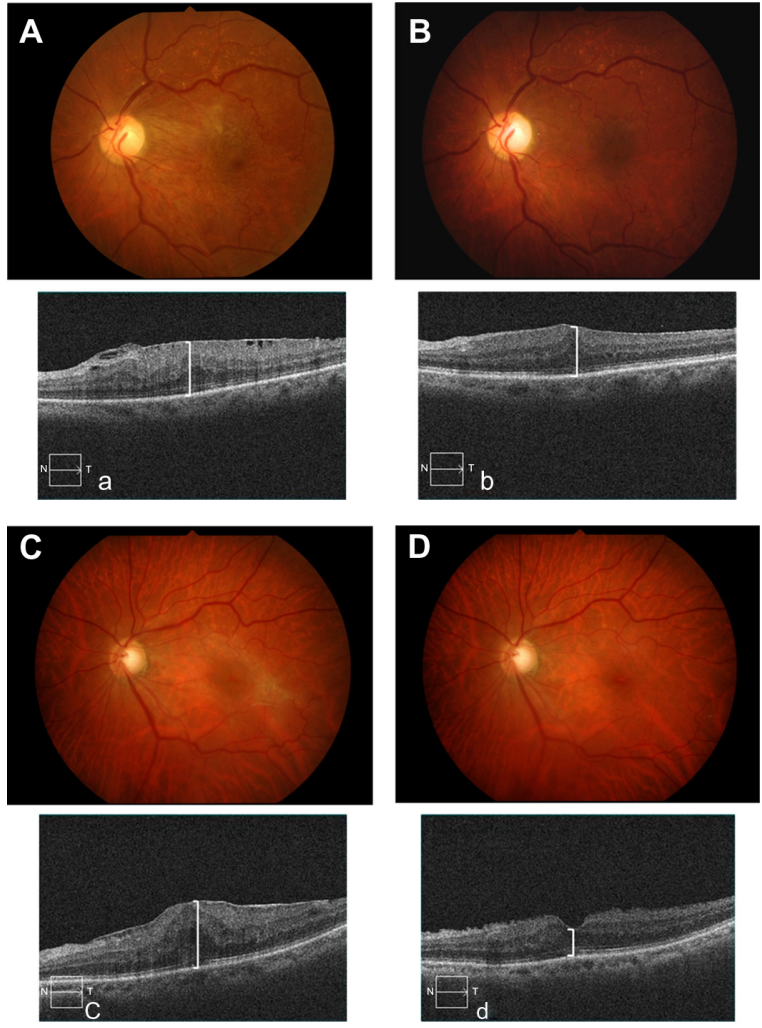

Figure 3 Fundus photography (A and $\mathbf{B}$ ), and horizontal optical coherence tomography (OCT) macular scans (a and b) before and I month after vitrectomy and removal of epiretinal membrane (nontreatment). Fundus photography (C and D), and horizontal OCT macular scans (c and d) before and I month after vitrectomy and removal of epiretinal membrane (dorzolamide treatment).

Note: White lines indicate central macular thickness.

Abbreviation: OCT, optical coherence tomography. 


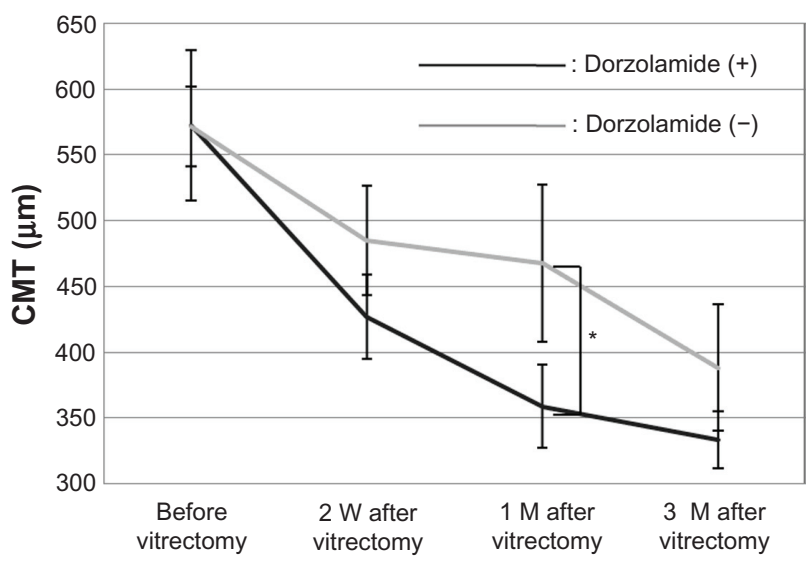

Figure 4 Mean CMT preoperatively and at 2 weeks (W), and I and 3 months (M) after surgery was not significantly different between the treatment and control groups, but the difference was statistically significant I month after surgery. Note: *Significant at $P<0.05$.

Abbreviation: CMT, central macular thickness.

day of oral prednisone and $20 \mathrm{mg} /$ week of intramuscular methotrexate, addition of tocilizumab, an anti-interleukin-6 receptor antibody, improved the acute-phase response (erythrocyte sedimentation rate and C-reactive protein) after 3 months of treatment. ${ }^{20}$ In the present study, dorzolamide reduced aqueous flare at 2 weeks after surgery. Topical dorzolamide may suppress postsurgical inflammation, and it has been reported that subretinal fluid is removed by inhibition of membrane-bound carbonic anhydrase IV in the retinal pigment epithelium.

However, it has also been reported that the response to carbonic anhydrase inhibitor therapy is better in patients with diffuse retinal pigment epithelial disease than in those with overt retinal vascular disease, such as diabetes or retinal vein occlusion. ${ }^{21}$ In this study, we chose patients who had

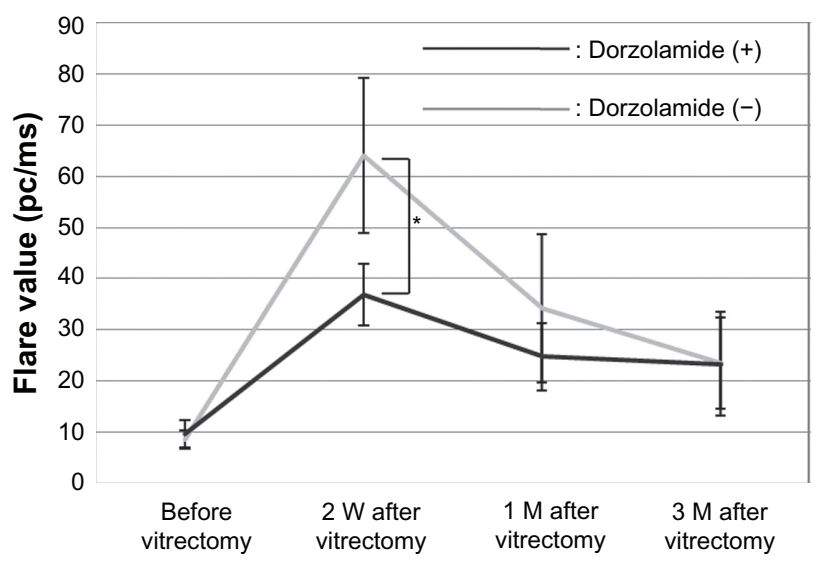

Figure 5 Mean aqueous flare preoperatively and at 2 weeks (W), and I and 3 months (M) after surgery was not significantly different between the treatment and control groups.

Notes: Mean aqueous flare at 2 weeks after surgery between the treatment group and the control group was statistically significant. *Significant at $P<0.05$. macular edema with epiretinal membrane. Epiretinal membranes are not usually associated with changes in the retinal pigment epithelium, so carbonic anhydrase inhibitors may act little through facilitation of transport across the retinal pigment epithelium. In addition, use of a topical carbonic anhydrase inhibitor decreases the risk of the well known systemic side effects of oral carbonic anhydrase inhibitor preparations. $^{21}$

Our study demonstrates that topical dorzolamide may reduce central macular thickness and aqueous flare in the early period following vitrectomy. Although further investigation of more cases is needed, this study suggests that topical dorzolamide can be efficacious in reducing macular edema during the early period following vitrectomy via its anti-inflammatory effects.

\section{Disclosure}

The authors report no conflicts of interest in this work.

\section{References}

1. Fine S, Brucker AJ. Macular edema and cystoid macular edema. Am J Ophthalmol. 1981;92:466-481.

2. Yanoff M, Fine S, Brucker AJ, Eagle RC, Jr. Pathology of human cystoid macular edema. Surv Ophthalmol. 1984;28 Suppl:505-511.

3. Gass JMD, Anderson DR, Davis EB. A clinical, fluorescein angiographic, and electron microscopic correlation of cystoids macular edema. Am J Ophthalmol. 1985;100:82-85.

4. Bresnick GH. Diabetic maculopathy. A critical review highlighting diffuse macular edema. Ophthalmology. 1983;90:1301-1317.

5. Bird AC. Retinal edema. Introduction to the first international cystoid macular edema symposium. Surv Ophthalmol. 1984;28 Suppl:433-436.

6. Tso MOM. Pathology of cystoid macular edema. Ophthalmology. 1982;89:902-915.

7. Schepens CL, Avila MP, Jalkh AE, Trempe CL. Role of the vitreous in cystoid macular edema. Surv Ophthalmol. 1984;28 Suppl:499-504.

8. Cox SN, Hay E, Bird AC. Treatment of chronic macular edema with acetazolamide. Arch Ophthalmol. 1988;106:1190-1195.

9. Farber MD, Lam S, Tessler HH, Jennings TJ, Cross A, Rusin MM. Reduction of macular edema by acetazolamide in patients with chronic iridocyclitis: a randomized prospective crossover study. $\mathrm{Br} J$ Ophthalmol. 1994;78:4-7.

10. Fishman GA, Gilbert LD. Acetazolamide for treatment of chronic macular edema in retinitis pigmentosa. Arch Ophthalmol. 1989;107: $1445-1452$.

11. Chen JC, Fitzke FW, Bird AC. Long-term effect of acetazolamide in a patient with retinitis pigmentosa. Invest Ophthalmol Vis Sci. 1990;31: 1914-1918.

12. Marmor MF. Hypothesis concerning carbonic anhydrase treatment of cystoid macular edema: example with epiretinal membrane. Arch Ophthalmol. 1990;108:1524-1525.

13. Apushkin MA, Fishman GA. Use of dorzolamide for patients with X-linked retinoschisis. Retina. 2006;26:741-745.

14. Genead MA, McAnany JJ, Fishman GA. Topical dorzolamide for treatment of cystoid macular edema in patients with choroideremia. Retina. 2012;32:826-833.

15. Ikeda Y, Hisatomi T, Yoshida N, et al. The clinical efficacy of a topical dorzolamide in the management of cystoid macular edema in patients with retinitis pigmentosa. Graefes Arch Clin Exp Ophthalmol. 2012;250:809-814. 
16. Kawai K, Ohashi H, Suzuki T, Kitagaki H, Fujisawa S. ヒトおよびマ ウス末梢血単核球の炎症性サイトカイン産生に及ぼす緑内障治 療薬の作用. [Effect of anti-glaucoma drugs on inflammatory cytokine production by human and murine peripheral blood mononuclear cells.] Nippon Ganka Gakkai Zasshi. 2010;114:669-677. Japanese.

17. Yang P, Fang W, Jin H, et al. Clinical features of Chinese patients with Fuchs' syndrome. Ophthalmology. 2006;113:473-480.

18. Ladas JG, Wheeler NC, Morhun PJ, et al. Laser flare-cell photometry: methodology and clinical applications. Surv Ophthalmol. 2005;50:27-47.
19. Wolfensberger TJ, Herbort CP. Treatment of cystoid macular edema with non-steroidal anti-inflammatory drugs and corticosteroids. Doc Ophthalmol. 1999;97:381-386.

20. Savino S, Daniela R, Dario R. Interleukin 6 blockade as steroid-sparing treatment for 2 patients with giant cell arteritis. J Rheumatol. 2011;38: 2080-2081.

21. Wolfensberger TJ. The role of carbonic anhydrase inhibitors in the management of macular edema. Doc Ophthalmol. 1999;97:387-397.
Clinical Ophthalmology

\section{Publish your work in this journal}

Clinical Ophthalmology is an international, peer-reviewed journal covering all subspecialties within ophthalmology. Key topics include: Optometry; Visual science; Pharmacology and drug therapy in eye diseases; Basic Sciences; Primary and Secondary eye care; Patient Safety and Quality of Care Improvements. This journal is indexed on

Submit your manuscript here: http://www.dovepress.com/clinical-ophthalmology-journal

\section{Dovepress}

PubMed Central and CAS, and is the official journal of The Society of Clinical Ophthalmology (SCO). The manuscript management system is completely online and includes a very quick and fair peer-review system, which is all easy to use. Visit http://www.dovepress.com/ testimonials.php to read real quotes from published authors. 